\title{
Chief Editor's Introduction
}

\section{Dr. Hamada Hamid Altalib}

In this issue of the Journal of Muslim Mental Health, all the original research uses qualitative methodology. Initially this seemed to be a coincidence; however, clearly the proportion of high quality qualitative research has increased in the last several years. Researchers are increasingly recognizing the value of indepth interviews, focus groups, and ethnography in describing the diversity of Muslim experiences. While qualitative studies tend to include a relatively small number of participants, the themes that emerge from the interviews inform clinicians and researchers of the complex ways people grapple with spirituality, culture, religion, and mental health.

Elkassem and colleagues provide a review of Islamophobia and mental health literature in "Growing Up Muslim: The Impact of Islamophobia on Children in a Canadian community." The researchers also collected experiences of Canadian Muslim kids who attend an Islamic elementary school. They describe how the children navigate the multiple dimensions of their identity, how they understood the recent Quebec City mosque shooting, and offer recommendations on how to engage young Muslims in conversations about their identity and culture.

In "An Exploration of the Help-Seeking Behaviors of Arab-Muslims in the U.S.: A Socio-ecological Approach", Alhomaizi and colleagues explore the helpseeking attitudes and behavior of Arab-American Muslims by interviewing attendees of the local Muslim Cultural Center and key informants (including imams and mental health professionals). Themes that emerged from the interviews include the layers of stigma, the role of mental health literacy, religious attitudes, and gender norms that inform help-seeking behavior among American Muslims.

“Beyond Cultural Sensitivity': Service Providers' Perspectives on Muslim Women Experiences of Intimate Partner Violence" focuses on social service providers' experiences with immigrant Muslim women in Canada. Milani and colleagues recruited participants from what they describe as a "Muslimoriented" women's shelter. They described their clients' experiences with accul- 
turation and postulated how collectivist, patriarchal culture and the values of honor and shame shape women's abuse experience and help-seeking behavior.

Moodley and colleagues produced the final original research work in this issue, "Conceptions of Depression of Muslim Clergy in a Faith-based Organization in South Africa". While there is a growing literature on the role of clergy, imams, and Muslim chaplains in mental health settings, there are very few studies on Muslim clergy's attitudes on mental health. Participants interviewed for this study were Muslim clerics and imams of Indian origin and live in South Africa. The authors demonstrate the interesting dynamic between clergies' biomedical, spiritual, and stress models of "depression". The authors argue that the "westernized disciplines" medicalization of emotional distress is demonstrated in the Islamic clerics' appropriation of biomedical conceptions mental illness.

Long and Ansari describe the history of Islamic chaplaincy as a profession in their Faith-Based Practice article. They trace the history of pastoral care and, in particular, Islamic chaplaincy in the U.S.. They argue that Muslim chaplains are uniquely positioned to integrate tradition Islamic spiritual sciences with contemporary social science in delivering mental health care.

While mental health professionals may be more accustomed to reading quantitative research, the themes and results of these studies should demonstrate the nuance that emerge from qualitative research. Furthermore, for clinicians, the narrative style of qualitative studies should resonate as voices of research participants reflects our clients' experiences. Perhaps the experiences shared by participants in these studies will help clinicians have a deeper appreciation of their clients' social and cultural context. 